\title{
LA DISMINUCIÓN DE INMIGRATES ESPAÑOLES EN FRANCIA
}

POR

\author{
JUAN DAVID SEMPERE SOUVANNAVONG
}

\section{Introducción}

Hace ya casi una generación que España dejó de ser bruscamente un país de emigración masiva, desde entonces la emigración exterior de españoles se ha paralizado casi totalmente con lo que en la actualidad se puede considerar que es un fenómeno residual. El estudio de todo lo relativo al modelo de esta emigración masiva (las causas, las etapas, la integración, el comportamiento de las generaciones siguientes, el retorno al país de origen) se impone en un momento en el que España se ha confirmado - desde hace ya casi una década - como un claro país de llegada para inmigrantes de regiones menos desarrolladas y donde por otra parte ya son numerosos los trabajos sobre la inmigración y la integración de los extranjeros.

Debido tanto a su proximidad geográfica como a su política migratoria, Francia ha sido un destino privilegiado para la emigración española del siglo xx. Los censos nacionales más recientes muestran que, después de Argentina, Francia es el país donde residen más españoles. Es además un país que desde muy antiguo ha conocido diversas oleadas de

Juan David Sempere Souvannavong: Departamento de Geografía Humana. Universidad de Alicante.

Estudios Geográficos

Tomo LXI, 2000, n. ${ }^{\circ} 239$, abril-junio 
inmigrados ${ }^{1}$ españoles y en el que éstos han terminado por conseguir, en líneas generales, un nivel de integración social y económica satisfactorio.

El caso de Francia es, pues, un ejemplo importante para observar la evolución y las dificultades de un movimiento migratorio terminado y de unos procesos de integración ya avanzados, pero algunas de cuyas etapas y características se están repitiendo actualmente en muchos otros lugares del mundo.

En este artículo se describe, a través de los cuatro últimos censos de población franceses (desde 1968 a 1990) ${ }^{2}$ cómo, por dónde y por qué la población española de Francia ha disminuido de manera tan contundente (anexo 1). En los veintidós años que separan ambos registros, el número de españoles censados se ha dividido casi por tres, siendo éste el colectivo de extranjeros en Francia que más se ha reducido en cifras absolutas y relativas durante este período (figura 1). Es la razón por la que se califica la evolución del colectivo español de Francia como un claro retroceso.

\section{Los censos como fuente para el estudio de la inmigración}

Puede parecer que los censos de población son una fuente muy rígida para el estudio de los movimientos migratorios; en algunos países sin fuerte tradición inmigratoria, como España, son de hecho una base insuficiente y sobre todo demasiado espaciada para un análisis adecuado de un fenómeno que está cambiando a gran velocidad desde principio de la década de los años 1990.

Sin embargo, tratándose de un estudio en gran parte evolutivo, las publicaciones de los censos franceses resultan una fuente fiable e ineludible. En este país los datos del censo son — sin tener en cuenta los del

${ }^{1}$ Este trabajo se ha realizado a partir de los censos del INSE (Institut National des Statistiques Economiques), es la razón por la cual la perspectiva adoptada es la francesa. En consecuencia, los españoles de Francia no son emigrados sino inmigrados.

2 Se empieza en 1968 porque además de ser el año del primer censo en cuyas publicaciones se detalla el número de españoles que hay en cada departamento, es también el año que marca el momento de máxima expansión del número de españoles en Francia.

1990 es el año del último censo realizado hasta el momento. Desde entonces el INSEE (1997a) no ha dado más que estimaciones menos fiables del número de españoles en Francia. 
Ministerio de Interior - casi la única fuente y el mejor medio para conocer las poblaciones de residentes extranjeros (Labat, 1993a: 37), para poder compararlas y para seguir la evolución que ha tenido cada uno de los principales colectivos. Desde el censo de 1851 se publican cifras sobre las principales nacionalidades que hay en Francia, lo cual confiere a la información sobre extranjeros del censo una antigüedad envidiable.

No obstante, aunque este artículo se basa en los censos, no es posible seguir sin manifestar el grave problema que éstos plantean para conocer la verdadera realidad de los extranjeros en Francia. En su voluntad de integrar, Francia tiene, como se va a ver más adelante, un código de la nacionalidad relativamente asequible a los inmigrados. Por otra parte en el cuestionario de los censos la pregunta relativa a este aspecto que se realiza no es «¿cuál es su nacionalidad?», sino «¿tiene la nacionalidad francesa?». Este detalle hace que las muchas personas que tienen más de una nacionalidad no puedan contestar por lo que sienten, sino estrictamente por si tienen o no la ciudadanía francesa. Esto no es involuntario, está perfectamente en regla con la legislación que sobre este punto es explícita, concluyente y no presenta ninguna posibilidad de confusión: cualquier francés puede tener otra u otras nacionalidades, pero en este caso debe obligatoriamente prevalecerse en Francia de su nacionalidad francesa ${ }^{3}$. En consecuencia, más que contabilizar el número de extranjeros, cualquier estadística francesa contabiliza a las personas que no tienen la nacionalidad.

Las repercusiones de todo ello es que, aunque en los censos aparezcan algunas estadísticas sobre los franceses por adquisición en función de la nacionalidad anterior, las cifras censales dan un reflejo de las poblaciones extranjeras correcto, con arreglo a la legislación, pero bastante deformado con relación a la realidad cotidiana de estos inmigrados y probablemente también con relación a la sociedad misma. Como se verá más adelante, esta circunstancia afecta de manera muy especial a los colectivos de europeos inmigrados desde hace tiempo y entre ellos a los españoles: en 1990 el grupo de los españoles que se han hecho franceses supera en efecto ampliamente -en casi un 40\% — al grupo de los españoles que no han adquirido la nacionalidad francesa.

${ }^{3}$ Además, sólo se puede dejar de ser francés si se repudia esta condición, y sólo es válida la renuncia que se realiza ante un juez o un cónsul francés en el extranjero. 
Por eso, y aunque sólo sea por completar los datos con los que se ha trabajado, hay que revelar las cifras que sobre la población española de Francia ofrecen otras fuentes:

Al 31 de diciembre de 1991, un año después del último censo, el Ministerio de Interior francés contabilizaba 264.7007 españoles con permiso de residencia. Una cifra que varía mucho de un año a otro (en 1992 eran 246.342) y que además tiene la desventaja de no tener en cuenta a los menores de edad - que no necesitan permiso- ni a los «irregulares» sin duda numerosos por la falta de control y de presión que hay sobre los ciudadanos de la Unión Europea.

Tras una larga puesta en orden de los archivos consulares ${ }^{4}$, el Ministerio de Asuntos Exteriores español elevó en 1993 a 410.959 el número de españoles inscritos en los registros consulares de España en Francia. Es una cifra que tampoco incluye a los «irregulares», esta vez porque no se dan de alta en los consulados, pero que presenta la ventaja de coincidir prácticamente con los 412.785 inmigrados españoles del censo de 1990 (cuadro I), es decir con el número de los españoles o franceses de origen español que han nacido fuera de Francia pero que residen en ella.

Habiendo visto datos de los consulados, de los censos (cuadro I) y del Ministerio de Interior francés, parece creíble que en Francia el total de los exclusivamente españoles se sitúe en torno a las 250.000 personas y el total de los españoles, con o sin la nacionalidad francesa, sea con cierta lógica próximo al de los inmigrados, algo superior a las 400.000 personas.

\section{El ciclo de la inmigración española en Francia}

La inmigración española en Francia es un fenómeno antiguo y muy completo cuya intensidad se ha mantenido hasta las manifestaciones de la crisis de 1973 en las economías occidentales. A lo largo de más de un siglo su presencia se ha consolidado en casi todo el país, se ha implicado en los principales ámbitos de la economía y ha conocido una incuestionable promoción social.

${ }^{4}$ Datos facilitados por responsables de la Federación de Asociaciones y Centros de Españoles de Emigrantes en Francia (FACEEF). 
A medidados del siglo XIX ya aparecen varias decenas de miles de españoles en Francia. Ha habido varias etapas, entre las que cabe distinguir:

a) La inmigración de principios del siglo xx atraída por la demanda de mano de obra para la agricultura y las industrias, sobre todo durante la Primera Guerra Mundial.

b) La llegada masiva derivada de la guerra civil española.

c) La inmigración de trabajadores que siguió a la instalación del Plan de Estabilización español en 1959 y que se dilató hasta la ruptura de los años 1970.

Con todo ello los españoles en Francia alcanzaron en 1968 su máximo número: más de 600.000 censados, casi un cuarto del total de los extranjeros, y un 1,22\% de la población total del país.

A partir de entonces empieza la última etapa de esta evolución, una etapa en la que, como ilustran los gráficos, el número de españoles ha descendido constantemente, y desde 1975 lo ha hecho de manera aún más acentuada, ya que el colectivo se ha ido reduciendo en un tercio en cada uno de los dos últimos intercensales. En la actualidad su total se encuentra al mismo nivel que en tiempos de la I Guerra Mundial, mientras que en cifras relativas al conjunto de extranjeros -6\%-, los españoles no estaban a unos niveles tan bajos desde el censo de 1866 .

Debido a la edad avanzada que tiene este colectivo en 1990, a su creciente integración y a la escasa emigración que hay en España, es más que probable que para el próximo recuento censal el número de españoles siga disminuyendo y vuelva a una cifra parecida a la que había a finales del siglo XIX. Aunque las características sociales y económicas de aquellos españoles ya tienen poco que ver con el colectivo actual, la vuelta a un grupo reducido permite hablar, por lo menos en lo referente al número, de un ciclo en la evolución de los españoles en Francia.

Desde otro punto de vista hay que resaltar cómo las diferentes oleadas de españoles en Francia han completado casi todas las tipologías de formas de movimientos migratorios posibles ${ }^{5}$, con lo que desde ese aspecto también se justifica que se trata de un movimiento completo.

${ }^{5}$ Siguiendo las clasificaciones que ofrece G. Simón en su manual sobre las migraciones internacionales (1995: 29-54). 
Observando las motivaciones, la mayoría de los inmigrados españoles que hay en Francia llegaron principalmente por razones económicas y laborales o familiares, pero no se debe olvidar el número de españoles que durante años vinieron como exiliados y refugiados. La mayoría de los autores cifran en 470.000 el número de la masiva y desordenada llegada que se dio a partir de los últimos meses de la guerra civil; aunque la mayoría no tardaron en re-emigrar o en volver a España, muchos de ellos se instalaron en Francia. Ésta no ha sido la única llegada de refugiados españoles: cuando en 1962 se independizó Argelia, una pequeña parte del casi un millón de pieds-noirs que llegaron a Francia huyendo de la creación del nuevo Estado, aún eran españoles, y una parte mucho más importante eran hijos de españoles o franceses de origen español.

Actualmente, con la creciente movilidad de estudiantes en la Unión Europea, hay que destacar las migraciones por motivo de estudios que también conciernen a un cierto número de españoles. Francia es en efecto, después de Estados Unidos, el país que más estudiantes atrae, en 1990, casi un $12 \%$ de esta movilidad se realizaba hacia Francia (Simon, 1995: 34).

Si lo que se clasifica son las competencias laborales, es cierto que la mayoría de estos inmigrados han sido mano de obra poco cualificada $u$ obreros especializados para la agricultura de las regiones del sur de Francia, en un tiempo dinámica y competitiva, o para la industria y el pequeño servicio de las grandes ciudades y del tercio norte del país en los años 1960. Pero la antigüedad, la amplitud de la colonia y la proximidad entre los dos países hace que no sea difícil encontrar trabajadores cualificados atraídos por los salarios en el mundo empresarial o personas que inmigran de manera independiente para realizar actividades muchas veces relacionada con la población española de Francia (turismo, comercio, restauración...).

Si nos detenemos en el tiempo de migración, los españoles han abarcado como ningún otro grupo de extranjeros, todo el abanico de migraciones. Una parte muy importante se han instalado definitivamente, como lo demuestra la proporción de franceses de origen español señalada anteriormente, muchos otros han venido temporalmente, por períodos que van desde pocos meses hasta temporadas tan largas como los años que duró la etapa política del General Franco. Con la avanzada edad del colectivo crece el número de jubilados y el de las 
personas que viven entre los dos países. Por último están las migraciones estacionales cuyo máximo exponente es la vendimia en el sur de Francia, que cada otoño sigue atrayendo a varios miles de españoles, pero que ya no son ni la sombra de las decenas de miles de personas que en los años 1960 y 1970 cruzaban la frontera para cosechar la uva.

Desde la crisis económica de los años 1970 se ha dado un vuelco en el sistema migratorio mundial, la situación jurídica se ha transformado en un aspecto cada vez más trascendental de los movimientos migratorios. Aunque debido al contexto internacional la inmigración clandestina de españoles no ha sido ni tan dura ni tan numerosa como es actualmente la de otros colectivos, la «inconcordancia» de las cifras que se dan más adelante evidencial que hubo un movimiento de irregulares considerable. En el extremo opuesto, también ha habido una inmigración que en épocas concretas, como durante la Primera Guerra Mundial, ha sido incluso «mucho más que regular», ha sido ordenada y dirigida por por el propio gobierno francés.

La población española que hay en Francia es, pues, el producto de estos flujos tan diversos que se han ido dando a lo largo de todo un siglo. Pero el censo de 1975 empieza a mostrar una ruptura sin precedentes. Desde ese año, en que se superponen el final de la emigración masiva y el cierre fronterizo de los países tradicionales de inmigración, se inicia la última etapa del ciclo, en la que la población española en Francia disminuye mediante el retorno y la integración en la sociedad francesa. Esta fase coincide con los años de la gran transformación del sistema migratorio francés y europeo en general, con los años en que se pasa de una inmigración dominada desde hace mucho tiempo por los europeos, sobre todo italianos y españoles, al sistema actual, mucho más abierto, en el que predominan magrebíes y portugueses y en el que ganan importancia los colectivos provenientes de zonas muy lejanas. La figura 1 ilustra bien este cambio, ya que muestra cómo los españoles han descendido de la primera a la quinta plaza entre los colectivos extranjeros en Francia, y, además cómo éstos — aún más que los italianos - han seguido desde 1968 una trayectorial frontalmente opuesta a todos los demás colectivos importantes extranjeros en Francia. 


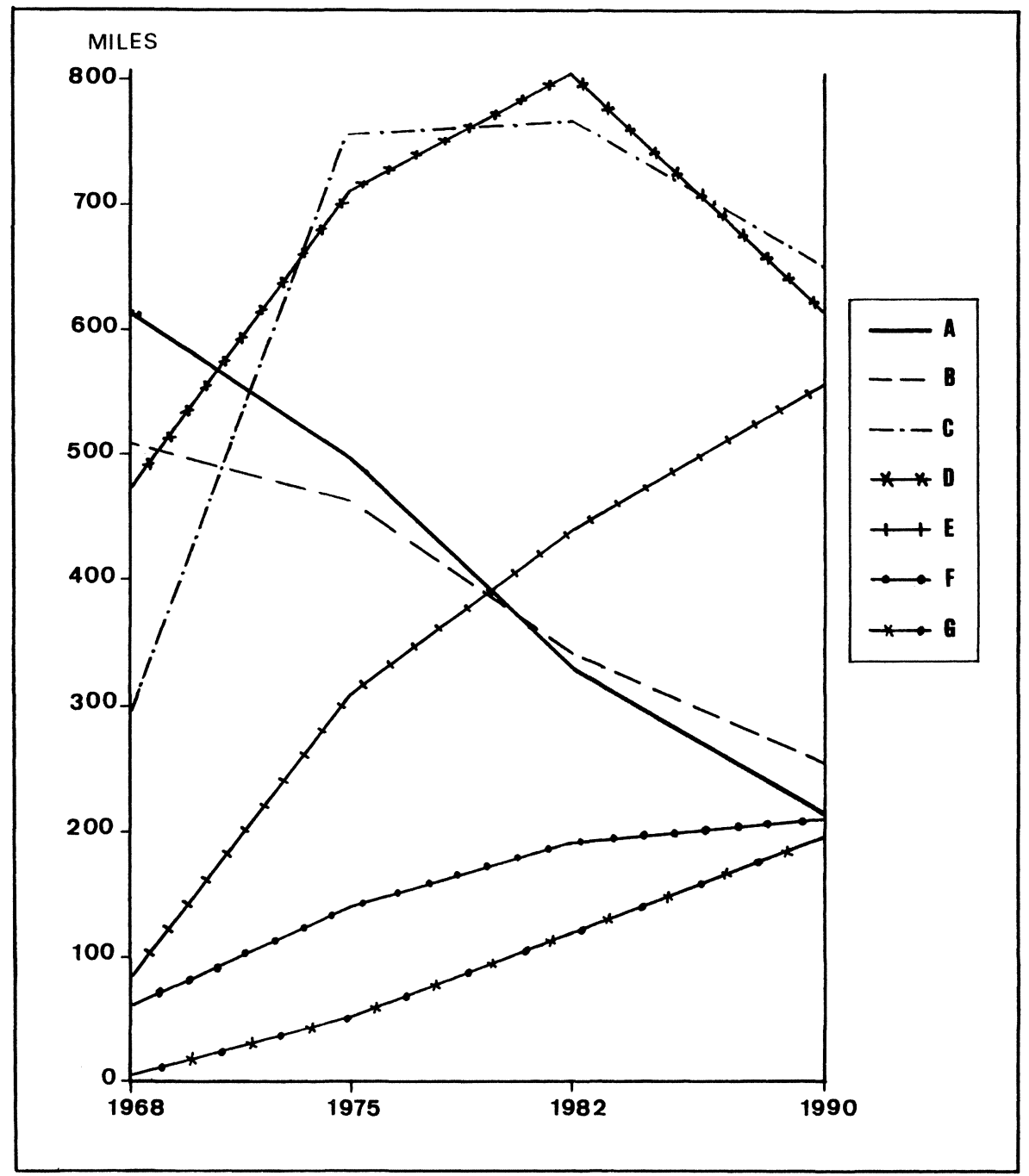

FIG. 1. Evolucion en cifras absolutas de la población española y de los otros seis principales colectivos de extranjeros censados en Francia desde 1968. A: españoles; B: italianos; C: portugueses; D: argelinos; E: marroquíes; F: tunecinos, y G: turcos. Fuente: Censo población de 1990. 


\section{Causas de disminución de los españoles en Francia}

Las cifras brutas dicen que de 1968 a 1990 el colectivo de los españoles en Francia ha descendido de 607.184 a 216.047 personas, es decir que se ha dividido casi por tres.

Para explicar esta reducción hay que recurrir a los elementos demográficos que hacen variar una población y también a una causa de origen político ya mencionada: las nacionalizaciones. Se tendrá en cuenta, pues, el saldo migratorio, el saldo natural y, además, la adquisición de la nacionalidad francesa por parte de los españoles.

Con el ánimo de cuantificar o al menos de evaluar, en la medida de lo posible, el peso relativo de cada una de estas razones, hemos tratado de calcular a partir del último intercensal (1982-90), el número de bajas españolas en Francia que se puede imputar a dos de estas causas.

\section{CuAdro I}

EVOLUCIÓN DE LOS ESPAÑOLES, DE LOS INMIGRADOS Y DE LOS FRANCESES DE ORIGEN ESPAÑOL EN LOS CUATRO ÚLTIMOS CENSOS DE POBLACIÓN

\begin{tabular}{lrrrr}
\hline & $\mathbf{1 9 6 8}^{\mathbf{6}}$ & $\mathbf{1 9 7 5}$ & $\mathbf{1 9 8 2}$ & $\mathbf{1 9 9 0}$ \\
\hline Españoles (A) & 607.184 & 497.480 & 327.156 & 216.047 \\
Variación & $\mathbf{3 7 , 5 \%}$ & $-\mathbf{1 8 , 5 \%}$ & $-\mathbf{3 4 , 2 \%}$ & $-\mathbf{3 4 , 0 \%}$ \\
Franceses de origen español (B) & 239.280 & 261.145 & 269.000 & 302.176 \\
Variación & $\mathbf{+ 3 1 , 5 \%}$ & $\mathbf{+ 9 , 1 \%}$ & $\mathbf{+ 3 , 0 \%}$ & $\mathbf{+ 1 2 , 3 \%}$ \\
Total (A+B) & 846.464 & 758.625 & 596.156 & 518.223 \\
Variación & $\mathbf{3 5 , 7 \%}$ & $-\mathbf{1 0 , 4 \%}$ & $-\mathbf{2 1 , 4 \%}$ & $-\mathbf{1 3 , 1 \%}$ \\
Inmigrados españoles $^{7}$ & - & 609.515 & 485.764 & 412.785 \\
Variación & - & - & $-\mathbf{2 0 , 3 \%}$ & $-\mathbf{1 5 , 0 \%}$ \\
\hline
\end{tabular}

Fuente: Censos de Población de Francia.

\footnotetext{
${ }^{6}$ En 1962 se censaron 441.658 españoles y 181.897 franceses de origen español. al no disponerse para ese año del número de franceses de origen español nacidos fuera de Francia, no se ha puesto el número de inmigrados.

${ }^{7}$ Por inmigrados se entiende la suma de los españoles y franceses de origen español que han nacido fuera de la Francia metropolitana, y que residen en ella en el momento del censo.
} 
Las nacionalizaciones. Como se ha dicho más arriba, desde el siglo XIX Francia tiene con los inmigrados una agresiva política de integración. Los instrumentos predilectos de esta política son la educación de los hijos de inmigrados y las facilidades ${ }^{8}$ que al cabo de cierto tiempo se dan a los inmigrados para adquirir una nacionalidad tan atractiva como la francesa. Atractiva por que tanto en la actualidad como en el pasado es asequible, interesante (sobre todo para inmigrados originarios de Estados más pobres o inestables) y además compatible con cualquier otra nacionalidad, lo que sin duda resta muchas reticencias a la hora de empezar a tramitar los papeles. Por estas razones, los inmigrados no suelen rechazar la posibilidad de adquirir ellos mismos o sus hijos esta condición.

Los españoles y los italianos siempre han sido uno de los objetivos preferidos de estas políticas integradoras: en 1990 sólo son el $13 \%$ del colectivo extranjero de Francia, mientras que los que se han hecho franceses representan un $41 \%$ de los franceses por adquisición. Durante la colonización francesa de Argelia los españoles ya fueron nacionalizados masivamente sin que, a pesar del malestar, el gobierno español se esforzara en frenar esta hemorragia ${ }^{9}$. Con los inmigrados del siglo $\mathrm{xx}$ al territorio de la metrópoli, se ha vuelto a dar una situación parecida sin que las autoridades españolas hayan hecho algo contundente por impedirlo o por aclarar las confusiones administrativas ${ }^{10}$.

${ }^{8}$ Según el código francés de la nacionalidad, son automáticamente franceses todos los que han nacido de padre o madre francés, y por el doble ius solii, los que han nacido en Francia de una madre o de un padre extranjero pero nacido en Francia (incluida Argelia antes de la independencia).

Por otra parte se les atribuye - con condiciones que han sido modificadas varias veces y que han vuelto a cambiar en 1998- la nacionalidad a los hijos de extranjeros que han nacido en Francia y que han residido en el país durante la adolescencia (por nacimiento y residencia), la pueden adquirir los extranjeros que están casados con una persona francesa (por declaración) y la pueden solicitar los extranjeros adultos que satisfacen algunas condiciones de «integración» (por naturalización).

${ }^{9}$ La importantísima emigración levantina a la Argelia francesa hizo que durante todo el siglo XIX hubiera para las autoridades un auténtico «peligro español». Para contrarrestarlo, además de facilitar la naturalización, en 1889 se promulgó una ley según la cual todos los europeos que nacían en Argelia eran automáticamente franceses. En 1911 se censaron en el Oranesado 93.000 españoles, 92.000 franceses y 92.000 franceses de origen español (Stora, 1994: 31). Esta última cifra demuestra el éxito de esta política y explica por qué la población española y extranjera de Argelia terminó siendo extremadamente minoritaria.

${ }_{10}$ Según el Código Civil de España, la nacionalidad española sólo es compatible con la de países hispanoamericanos, Andorra, Filipinas, Guinea y Portugal; con la de Francia 
Las nacionalizaciones son, pues, las que justifican una proporción importante del descenso de la población española de Francia. En este país no hay reparo en decir que casi una tercera parte de los más de cuatro millones de inmigrados que hay, son de nacionalidad francesa. De éstos, casi una cuarta parte - 302.176 - son de origen español, es decir, inmigrados españoles que se han hecho franceses. Desde 1968 a 1990 son 178.674 los españoles que han adquirido la nacionalidad francesa. Es una parte importante $(45,7 \%)$ de los 391.137 españoles que faltan en el censo de 1990 con respecto al de 1968. En lo que respecta al último intercensal (1982-90) ha habido 33.317 nacionalizaciones, lo que representa una proporción muy cercana al $30 \%$ de la diferencia entre ambos censos (cuadro I).

Contrariamente al saldo migratorio que vamos a ver a continuación, los resultados relativos a la nacionalidad deben ser a la fuerza fiables, ya que por principio ésta sólo se puede obtener de manera regular.

El saldo migratorio. El retorno de los emigrantes a España es lo primero en lo que habitualmente se suele pensar para justificar el descenso de población española en Francia. Desde 1975, los retornos han sido especialmente importantes para la emigración española por toda Europa. Hasta la entrada de España en la Comunidad Europea los retornados han contado, además, con generosas subvenciones por parte de algunos gobiernos europeos. Desde los años 1970, Francia aplica estas políticas destinadas a disminuir el número de extranjeros. Pero como cabía esperar, estas medidas sólo han tenido un éxito relativo entre los inmigrados de los países que más se han desarrollado, precisamente los colectivos mejor integrados y más apreciados por los frances a tenor de las encuestas realizadas a este respecto (Girard, 74): los europeos, en particular italianos, y sobre todo portugueses y españoles.

Se puede esperar, pues, que una parte importante del descenso de los españoles se deba al retorno. En efecto, por primera vez desde medidados del siglo xIX, el saldo migratorio entre Francia y España ha vuelto a ser favorable a esta última, pero la cuantificación de este movi-

no lo es. Esto crea una importante confusión entre los españoles en este país, ya que cuando adquieren la nacionalidad francesa deberían de renunciar expresamente a la española. La mayoría de ellos obviamente no lo hacen, con lo que, en teoría, infringen la legislación española. 
miento es difícil y muy poco fiable. Las estadísticas del censo revelan que durante la década de los años 1980, Francia ha concedido a ciudadanos españoles una media anual de casi 700 primeros permisos de trabajo o de residencia, es en lo que se puede medir la inmigración regular y oficial de trabajadores y familiares, mientras que en los años 1960 esta media se acercaba a los 60.000 permisos. Son cifras que probablemente infravaloran la realidad; las últimas porque no cuentan a los clandestinos, sin duda muy numerosos, y las primeras porque además de eso, van decreciendo hasta perder realmente la credibilidad, entre otras razones porque a los familiares de trabajadores españoles que entran en Francia desde 1986 ya no se les exigen requisitos particulares y se hacen más difíciles de contabilizar. Aún así las diferencias son muy elocuentes e ilustran perfectamente la caída de la inmigración española en Francia.

Las bajas consulares, las altas en el padrón municipal o el número de personas que solicitan la ayuda al retorno, son la base de los datos oficiales para evaluar el flujo contrario, la emigración española desde Francia: el retorno. Para el mismo período (1981-1990) se ha producido una media anual de casi 3.700 bajas en los consulados españoles de Francia (DGM, 1995: 73). Pero es probable que estas cifras también infravaloren la realidad, y lo hagan aún más que en el caso anterior, pues el retorno de los emigrados es a menudo un movimiento que se realiza por vías familiares, es decir, el emigrado vuelve a España para trabajar o para jubilarse, con el apoyo sobre todo de amigos y familiares, y no siempre realiza todos los trámites administrativos. Muchos de ellos, con los que no se cuenta, viven además entre los dos países. Todo esto hace que el retorno de los emigrados no se pueda saber con seguridad desde una única fuente, con lo que es poco fiable y difícil de evaluar.

Con todo ello, pues, hacer un balance real no es posible, pero suponiendo que al menos sea representativo se puede destacar que, al menos, en lo que a cifras oficiales se refiere, durante los años 1980 el flujo de españoles que se han marchado definitivamente de Francia es, como mínimo, más de cinco veces superior al de los que oficialmente han llegado y han obtenido un permiso de trabajo o de residencia. Calculando la diferencia tenemos que durante el último intercensal (1982-90) hay un saldo neto anual de unas 3.000 personas favorables a España. Esto puede representar entre un 30\% y un 35\% del descenso de los inmigrados españoles entre 1982 y 1990, mostrado en el cuadro I.

$$
-364-
$$


El saldo natural. El saldo natural es un factor demográfico que por definición afecta a cualquier colectivo de individuos, pero que aquí no ha sido posible cuantificar directamente, ya que no se ha hallado información sobre la natalidad y la mortalidad de los españoles en Francia y si se hubiera hallado ésta no sería fiable. Por lo que se ha visto hasta aho$\mathrm{ra}$, se puede suponer que es el elemento que menos ha influido en el descenso de la población que observamos.

Es innegable que se trata de una población envejecida, su presencia en muchas regiones de francia se consolidó, como ya se ha visto, antes de la guerra civil española, y su momento de máxima expansión se remonta a hace ya más de una generación. Es pues de suponer que debido a esta razón la mortalidad será más elevada que la natalidad como cabe esperar en un grupo de estas características. Sin embargo, esta variable está muy alterada tanto por los retornos como por las nacionalizaciones que influyen sobremanera en las personas adultas inmigradas. Ni todos los inmigrados españoles mueren en Francia, ni los que lo hacen, lo hacen como españoles, con lo que no aparecen en el censo como pretendemos encontrarlos. Estas irregularidades reducen mucho la mortalidad de los españoles, lo que resta representatividad al saldo natural ya bastante desfigurado.

Por otra parte, los nacimientos de padre o de madre española en Francia sí que aparecen en el censo: de 1968 a 1990 han nacido en Francia 111.738 hijos de madre española, aunque desde 1975 han sido sólo 34.556. Pero todos estos niños nacidos en Francia prácticamente no pueden contabilizarse, ya que o son franceses por vía paterna, o se naturalizan al llegar a la mayoría de edad. La personas nacidas en Francia que se han mantenido españolas no son de hecho ni la cuarta parte 25.961 - de los hijos de españoles nacidos en Francia. Esta variabilidad tanto para los nacimientos como para las defunciones dejan claro que el movimiento natural es bastante difícil de seguir.

Sin embargo, con todo lo que hemos visto hay que recapitular diciendo que para el último período intercensal hemos evaluado la parte de las nacionalizaciones en la bajada de los españoles al menos en un $30 \%$, y la del saldo migratorio oficial en el descenso de los inmigrados en torno a un $30-35 \%$. Todo esto deja en torno a un 35-40\% para el saldo natural, y sobre todo para todos los movimientos que entre un censo y otro no han sido registrados.

Por todas estas razones, si se compara estrictamente el número de españoles, tenemos que el colectivo se ha divido por tres en menos de una 
generación. Esto nos llevaría a pensar con cierta satisfacción que una parte importante de éstos ha retornado a España, como de hecho ha sucedido. Pero ésa no es toda la realidad, hay que matizarla sabiendo que el descenso de los españoles no se debe sólo a las migraciones, sino también a las nacionalizaciones, y que si consideramos el total de la colonia española, es decir, la suma de los españoles y franceses de origen español, el descenso no ha sido tan importante, como bien muestra el cuadro I. En cifras relativas, el descenso entre 1968 y 1990 ha sido de un $65 \%$ para los españoles, pero sólo de un $39 \%$ en el total de los españoles y franceses de origen español, para los que la diferencia entre cada intercensal está bien lejos del tercio observado para los españoles exclusivamente.

Por otra parte, la figura 2 demuestra cómo sobre el conjunto de toda la población que estudiamos, la proporción de españoles (A) se ha reducido de manera evidente, mientras que la de los inmigrados españoles (C) se ha mantenido prácticamente estable.

Esto nos lleva a pensar que los españoles de Francia se han integrado en el país de destino y que no tienen intención de volver al país de origen, puesto que en 1990 ya hacía quince años que se inició el retorno masivo de los emigrantes españoles.

\section{El despoblamiento español de Francia}

Para ilustrar el descenso por regiones de la población española en Francia, se han realizado cuatro mapas en los que a nivel departamental se observa su presencia en cada uno de los censos (fig. 3).

Sólo se ha podido obtener la información respectiva a los españoles, pues las publicaciones del censo (ni siquiera las de 1990 que son las más completas) no ofrecen el número de franceses de origen español por departamentos, y aún menos el número de españoles y de franceses de origen español nacidos fuera de Francia, que sería necesario para tener la evolución de los inmigrados. La versión de los consulados podría haber sido más correcta, pero hay que indicar que los registros consulares no funcionan por departamentos, sino por circunscripciones consulares y cada una de las 14 que hay corresponde a un territorio que puede ser más pequeño que un departamento (como en el caso de Pau, Bayona o Hendaya) o agrupar, en la mayoría de los casos, varios departamentos. Por

$$
-366-
$$




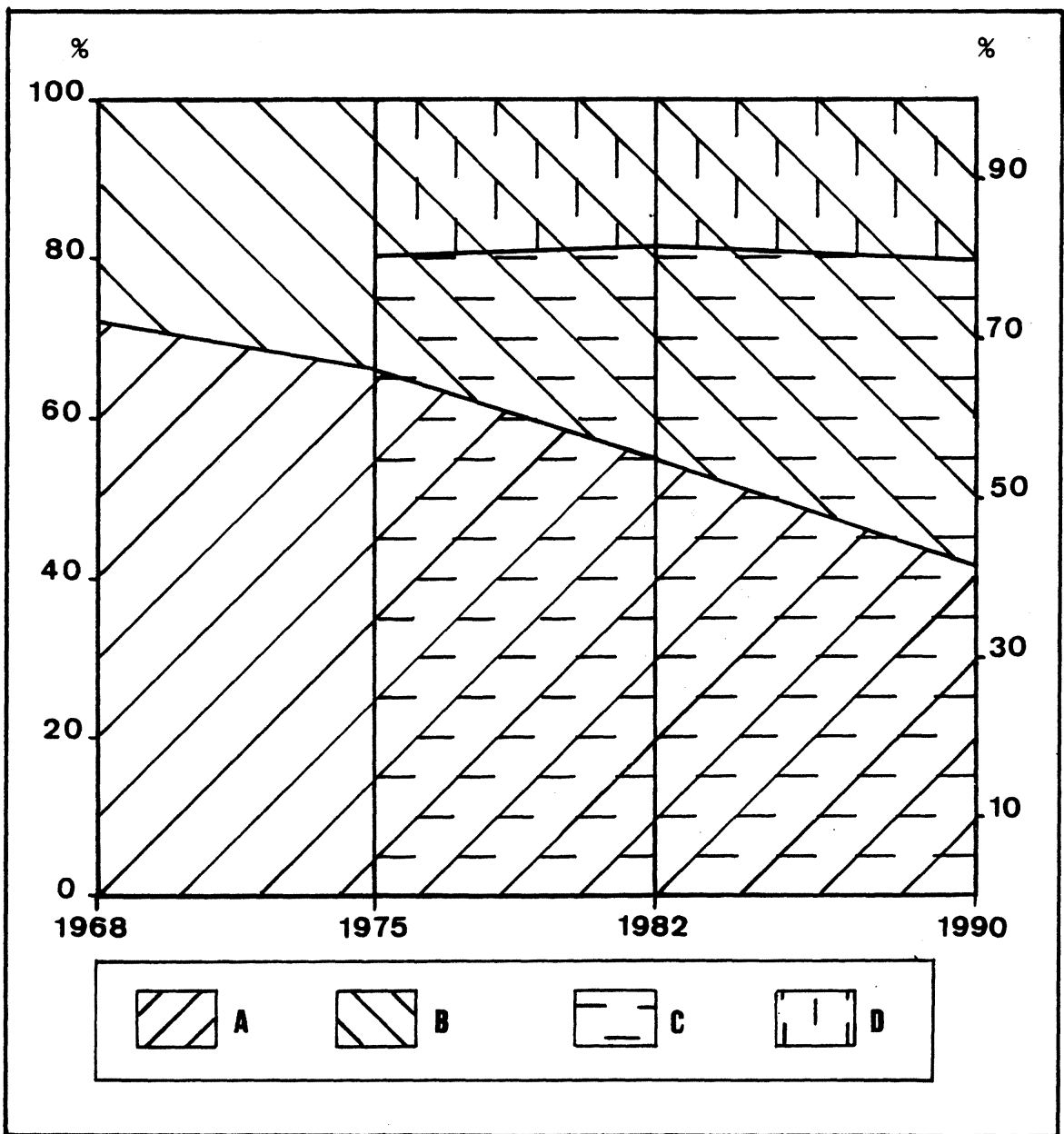

Fig. 2. Evolución, en porcentajes, de las distintas subpoblaciones del colectivo de españoles y de franceses de origen español, en relación al conjunto de esta población. A: españoles; B: franceses de origen español; C: españoles y franceses de origen español que han nacido fuera de Francia (inmigrados españoles) y D: españoles y franceses de origen español nacidos en Francia (no inmigrados). Fuente: Censo de población de 1990. 
otra parte, cada consulado tiene los datos propios, pero no los de toda Francia, y fuera de las estadísticas de Ministerio de Asuntos Exteriores no es posible tener los datos de conjunto y éstos vienen precisamente por países y por circunscripciones consulares y no en función de las divisiones administrativas de cada país.

En líneas generales se observa que en todos los departamentos la población española ha descendido de manera continuada desde el censo de 1968, pero es sólo después de 1975 cuando esta bajada se ha hecho más que significativa. En total, la población española se ha reducido en casi dos tercios entre 1968 y 1990, tanto en el ámbito estatal como a nivel departamental. De los 95 departamentos que hay en el territorio metropolitano francés, no sólo no hay ni uno que en veintidós años haya aumentado su población de españoles ${ }^{11}$, sino que en el departamento en el que ésta ha descendido menos lo ha hecho en más de un tercio. Son sólo ocho los departamentos en los que los españoles se han reducido a menos de la mitad, las dos terceras partes de éstos han visto bajar su número de españoles entre un 50 y $70 \%$ en los veintidós años que suman los tres últimos intercensales. La reducción ha sido, pues, sin ninguna excepción, regular y generalizada en toda Francia. Para ver en qué región ha descendido más, habrá que tener en cuenta, por una parte, que en valores relativos las diferencias entre las distintas regiones de Francia han sido bastante reducidas, y, por la otra, que tanto la distribución de las regiones donde más ha descendido el número de españoles como en las que más se ha mantenido es extremadamente irregular.

Tanto en 1968 como en el último censo, los principales colectivos de españoles se distribuyen en las mismas regiones: el tercio sur, sobre todo en los Pirineos y en el arco del Mediterráneo, en la región de París y en menor medida en la de Lyón. La zona de menos población aparece aún más clara, corresponde a todo el centro y la parte noroccidental de Francia, con las contadas excepciones de l'Ile de France y de la región de Clermont-Ferrand, que debido a su carácter industrial —es la capital de la empresa de neumáticos Michelin— ha atraído mucha mano de obra extranjera.

Lo que ha sucedido puede describirse, como indican los mapas, en que las zonas de presencia española se han «encogido» en torno a los

${ }^{11}$ Con escasísimas excepciones, desde 1968 ni siquiera entre dos censos sucesivos hay departamentos que hayan visto crecer su número de españoles. 


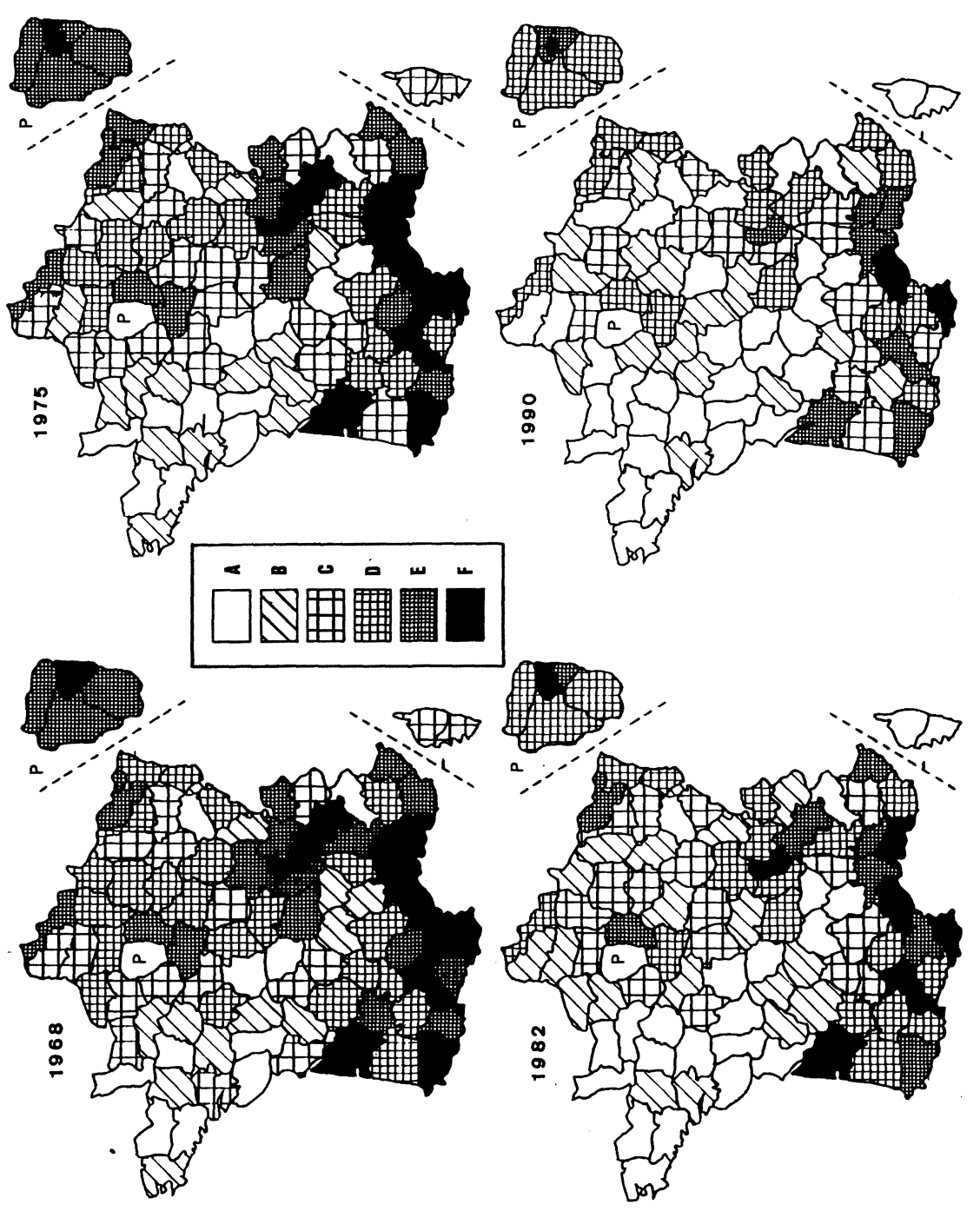

Fig. 3. Evolución por departamentos de la población española en Francia durante los cuatro últimos censos (anexo 1). A: 68-499 españoles; B: 500-999; C: 1.000-1.999; D: 2.000-4.999; E: 5.000-9.999, F: 10.000-65.512. Fuente: Censo de población de 1990 . 
ANEXo I

EVOLUCIÓN DEL NÚMERO DE ESPAÑOLES EN LOS

DEPARTAMENTOS Y REGIONES (EN CURSIVA) DE FRANCIA

SEGÚN LOS ÚLTIMOS CUATRO CENSOS (1968, 1975, 1982 Y 1990)

(Fuente: Censos de Población de Francia).

\begin{tabular}{|c|c|c|c|c|}
\hline Departamentos & 1968 & 1975 & 1982 & 1990 \\
\hline Bas-Rhin & 4.416 & 6.110 & 3.700 & 2.809 \\
\hline Haut-Rhin & 3.984 & 4.610 & 4.340 & 2.452 \\
\hline Alsace & 8.400 & 10.720 & 8.040 & 5.261 \\
\hline Dordogne & 2.152 & 1.755 & 960 & 520 \\
\hline Gironde & 24.244 & 18.645 & 13.740 & 9.104 \\
\hline Landes & 4.812 & 3.810 & 2.360 & 1.576 \\
\hline Lot-et-Garonne & 5.128 & 3.145 & 2.900 & 1.428 \\
\hline Pyrénées-Atlantiques & 16.540 & 14.010 & 9.920 & 7.800 \\
\hline Aquitaine & 52.876 & 41.365 & 29.880 & 20.428 \\
\hline Allier & 2.384 & 1.765 & 940 & 648 \\
\hline Cantal & 604 & 465 & 200 & 192 \\
\hline Haute-Loire & 764 & 535 & 180 & 256 \\
\hline Puy-de-Dôme & 8.584 & 7.140 & 2.800 & 2.341 \\
\hline Auvergne & 12.336 & 9.905 & 4.120 & 3.437 \\
\hline Côte-d'Or & 3.332 & 2.500 & 1.760 & 1.284 \\
\hline Nièvre & 1.548 & 1.215 & 1.040 & 321 \\
\hline Saône-et-Loire & 5.224 & 4.295 & 2.280 & 1.997 \\
\hline Yonne & 2.348 & 1.615 & 700 & 664 \\
\hline Bourgogne & 12.452 & 9.625 & 5.780 & 4.266 \\
\hline Côtes-du-Nord & 288 & 315 & 160 & 164 \\
\hline Finistère & 708 & 505 & 480 & 412 \\
\hline Ille-et-Vilaine & 676 & 605 & 780 & 280 \\
\hline Morbihan & 268 & 190 & 260 & 88 \\
\hline Bretagne & 1.940 & 1.615 & 1.680 & 944 \\
\hline Cher & 2.340 & 1.615 & 1.200 & 924 \\
\hline Eure-et-Loir & 1.928 & 1.325 & 1.000 & 748 \\
\hline Indre & 464 & 390 & 280 & 196 \\
\hline Indre-et-Loir & 2.072 & 1.420 & 1.140 & 672 \\
\hline Loir-et-Cher & 1.592 & 1.290 & 880 & 624 \\
\hline Loiret & 7.092 & 5.795 & 3.320 & 2.174 \\
\hline Centre & 15.488 & 11.835 & 7.820 & 5.338 \\
\hline Ardennes & 2.156 & 1.550 & 880 & 692 \\
\hline
\end{tabular}


ANExo I (continuación)

EVOLUCIÓN DEL NÚMERO DE ESPAÑOLES EN LOS

DEPARTAMENTOS Y REGIONES (EN CURSIVA) DE FRANCIA SEGÚN LOS ÚLTIMOS CUATRO CENSOS (1968, 1975, 1982 Y 1990) (Fuente: Censos de Población de Francia).

\begin{tabular}{|c|c|c|c|c|}
\hline Departamentos & 1968 & 1975 & 1982 & 1990 \\
\hline Aube & 2.380 & 2.005 & 1.360 & 888 \\
\hline Marne & 3.040 & 2.930 & 1.980 & 1.149 \\
\hline Haute-Marne & 1.552 & 1.025 & 940 & 476 \\
\hline Champagne-Ardenne & 9.128 & 7.510 & 5.160 & 3.205 \\
\hline Corse-du-Sud & - & - & 240 & 204 \\
\hline Haute-Corse & - & - & 140 & 224 \\
\hline Corse & 1.560 & 1.325 & 380 & 428 \\
\hline Doubs & 3.392 & 3.115 & 1.540 & 1.108 \\
\hline Jura & 972 & 925 & 520 & 368 \\
\hline Haute-Saône & 492 & 480 & 140 & 244 \\
\hline Territoire de Belfort & 952 & 910 & 620 & 416 \\
\hline Franche-Comté & 5.808 & 5.430 & 2.820 & 2.136 \\
\hline Ville de Paris & 65.512 & 54.275 & 36.600 & 22.395 \\
\hline Seine-et-Marne & 9.384 & 8.130 & 6.280 & 4.384 \\
\hline Yvelines & 9.348 & 8.935 & 4.580 & 4.160 \\
\hline Essonne & 6.368 & 6.180 & 4.000 & 3.012 \\
\hline Hauts-de-Seine & 16.280 & 14.905 & 10.740 & 7.840 \\
\hline Seine-Saint-Denis & 19.528 & 18.170 & 11.620 & 9.188 \\
\hline Val-de-Marne & 10.148 & 9.285 & 7.260 & 5.005 \\
\hline Val-d'Oise & 7.960 & 7.000 & 4.600 & 3.588 \\
\hline Ille-de-France & 144.528 & 126.880 & 85.680 & 59.572 \\
\hline Aude & 17.956 & 12.495 & 7.920 & 4.428 \\
\hline Gard & 17.828 & 13.405 & 7.640 & 5.433 \\
\hline Hérault & 39.340 & 30.100 & 17.120 & 11.148 \\
\hline Lozère & 828 & 450 & 380 & 144 \\
\hline Pyrénées-Orientales & 32.864 & 25.685 & 18.180 & 12.396 \\
\hline Languedoc-Roussillon & 108.816 & 82.135 & 51.240 & 33.549 \\
\hline Corrèze & 1.792 & 1.195 & 800 & 420 \\
\hline Creuse & 352 & 120 & 60 & 92 \\
\hline Haute-Vienne & 1.184 & 930 & 680 & 432 \\
\hline Limousin & 3.328 & 2.245 & 1.540 & 944 \\
\hline Meurthe-et-Moselle & 2.832 & 2.530 & 1.340 & 1.124 \\
\hline
\end{tabular}

Fuente: Censos de Población de Francia. 
ANexo I (continuación)

EVOLUCIÓN DEL NÚMERO DE ESPAÑOLES EN LOS

DEPARTAMENTOS Y REGIONES (EN CURSIVA) DE FRANCIA

SEGÚN LOS ÚLTIMOS CUATRO CENSOS (1968, 1975, 1982 Y 1990)

(Fuente: Censos de Población de Francia).

\begin{tabular}{|c|c|c|c|c|}
\hline Departamentos & 1968 & 1975 & 1982 & 1990 \\
\hline Meuse & 1.460 & 985 & 1.000 & 420 \\
\hline Moselle & 8.720 & 8.480 & 6.200 & 3.148 \\
\hline Vosges & 1.860 & 1.455 & 1.380 & 612 \\
\hline Lorraine & 14.872 & 13.450 & 9.920 & 5.304 \\
\hline Ariège & 5.820 & 4.220 & 3.060 & 1.588 \\
\hline Aveyron & 3.896 & 2.835 & 1.280 & 1.088 \\
\hline Haute-Garonne & 19.316 & 16.225 & 11.580 & 6.872 \\
\hline Gers & 3.500 & 2.360 & 2.000 & 872 \\
\hline Lot & 2.676 & 1.490 & 1.140 & 648 \\
\hline Hautes-Pyrénées & 8.512 & 6.395 & 3.480 & 2.816 \\
\hline Tarn & 6.760 & 5.360 & 2.480 & 2.008 \\
\hline Tarn-et-Garonne & 3.748 & 2.815 & 1.860 & 1.192 \\
\hline Midi-Pyrénées & 54.228 & 41.700 & 26.880 & 17.084 \\
\hline Nord & 8.844 & 7.955 & 4.380 & 3.364 \\
\hline Pas-de-Calais & 1.224 & 1.265 & 900 & 408 \\
\hline Nord-Pas-de-Calais & 10.068 & 9.220 & 5.280 & 3.772 \\
\hline Calvados & 1.032 & 840 & 420 & 352 \\
\hline Manche & 216 & 175 & 220 & 112 \\
\hline Orne & 572 & 585 & 260 & 252 \\
\hline Basse-Normandie & 1.820 & 1.600 & 900 & 716 \\
\hline Eure & 1.700 & 1.220 & 600 & 492 \\
\hline Seine-Maritime & 2.436 & 1.770 & 880 & 848 \\
\hline Haute-Normandie & 4.136 & 2.990 & 1.480 & 1.340 \\
\hline Loire-Atlantique & 1.220 & 880 & 720 & 548 \\
\hline Maine-et-Loire & 700 & 385 & 320 & 248 \\
\hline Mayenne & 148 & 135 & 120 & 68 \\
\hline Sarthe & 720 & 665 & 180 & 340 \\
\hline Vendée & 176 & 105 & 80 & 108 \\
\hline Pays de la Loire & 2.964 & 2.170 & 1.420 & 1.312 \\
\hline Aisne & 2.928 & 2.420 & 1.660 & 980 \\
\hline Oise & 4.160 & 3.285 & 1.860 & 1.608 \\
\hline Somme & 1.144 & 745 & 500 & 392 \\
\hline
\end{tabular}


ANEXo I (continuación)

EVOLUCIÓN DEL NÚMERO DE ESPAÑOLES EN LOS

DEPARTAMENTOS Y REGIONES (EN CURSIVA) DE FRANCIA SEGÚN LOS ÚLTIMOS CUATRO CENSOS (1968, 1975, 1982 Y 1990) (Fuente: Censos de Población de Francia).

\begin{tabular}{lrrrr}
\hline \multicolumn{1}{c}{ Departamentos } & $\mathbf{1 9 6 8}$ & $\mathbf{1 9 7 5}$ & $\mathbf{1 9 8 2}$ & $\mathbf{1 9 9 0}$ \\
\hline Picardie & 8.232 & 6.450 & 4.020 & 2.980 \\
Charente & 1.292 & 975 & 720 & 560 \\
Charente-Maritime & 1.268 & 935 & 480 & 388 \\
Deux-Sèvres & 328 & 205 & 240 & 132 \\
Vienne & 576 & 600 & 400 & 353 \\
Poitou-Charentes & 3.464 & 2.715 & 1.840 & 1.432 \\
Alpes-de-Haute-Provence & 2.944 & 1.890 & 1.500 & 612 \\
Hautes-Alpes & 476 & 385 & 220 & 209 \\
Alpes-Maritimes & 6.828 & 5.690 & 5.120 & 3.369 \\
Bouches-du-Rhône & 28.032 & 21.715 & 11.280 & 7.417 \\
Var & 7.636 & 6.095 & 3.680 & 2.264 \\
Vaucluse & 17.652 & 14.205 & 9.580 & 5.340 \\
Provence-Alpes-Côte-d'Azur & 63.568 & 49.980 & 31.340 & 19.211 \\
Ain & 6.104 & 5.370 & 4.020 & 2.6845 \\
Ardèche & 2.852 & 2.300 & 1.000 & 1.004 \\
Drôme & 5.088 & 3.100 & 2.600 & 1.876 \\
Isère & 12.880 & 11.265 & 6.700 & 3.956 \\
Loire & 6.380 & 5.020 & 2.820 & 1.996 \\
Rhône & 24.856 & 20.605 & 11.920 & 8.188 \\
Savoie & 1.836 & 1.490 & 800 & 648 \\
Haute-Savoie & 7.176 & 7.465 & 4.360 & 3.036 \\
Rhône-Alpes & 67.172 & 56.615 & 34.220 & 23.388 \\
& & & & \\
Total & $\mathbf{6 0 7 . 1 8 4}$ & $\mathbf{4 9 7 . 4 8 0}$ & $\mathbf{3 2 1 . 4 4 0}$ & $\mathbf{2 1 6 . 0 4 7}$ \\
\hline & & & &
\end{tabular}

centros importantes, Perpiñán, Montpellier y París cuyos departamentos son los únicos donde se han censado más de 10.000 españoles en 1990. Luego aún se puede destacar Burdeos, Pau, Toulouse, Marsella, Lyón y los tres departamentos que rodean la ciudad de París como núcleos secundarios. 
Determinar las regiones donde más se ha reducido la población española en cifras porcentuales es, como se ha dicho, más difícil debido a la irregular distribución de los departamentos en los que más se ha reducido. Parece que se sitúan preferentemente en las zonas periféricas del tercio sur y del centro del país, y en menor medida donde no hay importantes núcleos urbanos o donde el número de españoles no era demasiado importante. Pero hay excepciones muy notables, como París o Montpellier que no son periferia pero donde la bajada ha sido muy fuerte.

Las regiones que menos han bajado se sitúan sin motivo aparente en los extremos este y oeste de Francia, sólo cabe destacar la región de Alsacia donde la población española era y es relativamente importante y donde más se ha mantenido, puesto que en 1990 se censa más del $60 \%$ de la que había en 1968.

\section{Conclusión}

Después de Argentina, donde hay 270.000 españoles, Francia es el país del mundo en cuyo censo nacional aparecen más españoles. Sin embargo, esta afirmación hay que matizarla sabiendo que en este último país son más de 300.000 los españoles que han adquirido la nacionalidad francesa, pero que según los consulados no parecen haber abandonado automáticamente su condición de españoles.

Por otra parte, el número de inmigrados españoles en Francia se eleva a 412.785. La diferencia entre ambas cifras es ante todo una evidencia del esfuerzo que, mediante las nacionalizaciones, realiza Francia por integrar las poblaciones extranjeras. Sin embargo, esta situación no debe esconder la realidad social y personal de estas personas, pues en 1993 aún habían 410.959 españoles residentes en Francia registrados en los consulados españoles. Este hecho muestra cuantos de ellos siguen conservando su nacionalidad de origen, aunque no aparezcan como tales en el censo, y de alguna manera el apego que siguen teniendo en España.

Aun así resulta evidente que a lo largo de los tres últimos períodos intercensales, sobre todo de los dos últimos, el número de españoles y de franceses de origen español ha descendido en varios cientos de miles debido en buena parte al retorno y en una desconocida proporción al saldo natural de un colectivo ya en buena medida envejecido. 
Todo parece indicar que en los próximos años van a seguir descendiendo tanto la población de españoles en Francia a causa de las nacionalizaciones, como la de los inmigrados - españoles y franceses de origen español一, más lentamente, como consecuencia de las defunciones y de los retornos a España.

\section{BIBLIOGRAFÍA}

BERTRAND, Jean-Réné: «Bilan de l'emigration espagnole», Revue Géographique des Pyrénnées et du Sud-Ouest, núm. 3, 1979, pp. 385-405.

Dirección General De Migraciones (DGM): Anuario de Migraciones, 1995. Madrid, Ed. Dirección General de Migraciones, Ministerio de Asuntos Sociales, 1996, 606 pp.

DREYFuS-ARMAND, Geneviève: «La constitution de la colonie espagnole en France», Hommes et Migrations, núm. 1184, febrier 1995, pp. 6-12.

ESCRIBANO MORALES, Fátima: Movimiento migratorio español: emigración, retorno y población española en el mundo. VIII Pleno del Consejo General de la Emigración. Jornada sobre el retorno. Torremolinos (Málaga), 10-13 de noviembre de 1997, Ed. INE.

Gaso CuENCA, José Gabriel: L'émigration espagnole en France: éléments d'information, trabajo realizado para el Fond d'Action Sociale, marzo 1995.

GIRARD, Alain; CHARBIT, Yves et LAMY, Marie-Laurence: «Attitudes des français à l'égard de l'immigration étrangère. Nouvelle enquête d'opinion», Population, núm. 6, 1974, Ed. INED, pp. 1015-1069.

GulLLoN, Michelle: «Étrangers et français par acquisition, une lente diversification sociale (1982-1990)», Revue Européenne des Migrations Internationales, vol. 12, núm. 2, Poitiers, 1996, pp. 123-148.

HAUT CONSEIL À L'INTÉGRATION (HCI): La connaissance de l'immigration et de l'intégration: rapport au Premier Ministre, novembre 1991, París, La Documentation Française, $1992,146 \mathrm{pp}$.

JERMET, Guy: Les espagnols en France: immigration et culture, París, Ed. Ouvrières, Coll. L'évolution de la vie sociale, $1967,328 \mathrm{pp}$.

INSEE: Recensement de la population de 1990. Nationalité. Résultats de sondage au quart, París, INSEE, Coll. INSEE Résulats (núm. 217). Démographie-Société (núm. 21), novembre 1992.

— L L'estimation du nombre d'immigrés et d'enfant d'immigrés, París, INSE, Coll. INSEE méthodes, 1997a, 80 pp.

- Annuaire statistique de la France, 1997. París, INSEE, 1997b.

LABAT, Jean-Claude: «La population étrangère et son évolution», Donées Sociales, INSEE, 1993a, pp. 37-48.

- : «trangers et français par acquisition au recensement de 1990: les changements intervenus depuis 1968", in Droits et politiques de la nationalité en France depuis les anneés 60, Aix-en-Provence, Edisud, 1993b, pp. 61-69.

SEMPERE SovanNAVONG, Juan David: Los pieds-noirs en Alicante, las migraciones de la descolonización. Alicante, Ed. Secretariado de publicaciones de la Universidad de Alicante, 1998, $123 \mathrm{pp}$.

Simon, Gildas: Géodynamique des migrations intermationales dans le monde. París, Ed. Presse Universitaire de France, 1995, 429 pp.

Stora, Benjamín: Histoire de l'Algérie coloniale. París, Ed. La Découverte, 1993, 130 pp. 
RESUMEN: A pesar de los problemas jurídicos que presentan los censos de población francesa a la hora de contabilizar el número de extranjeros, éstos son una buena fuente para conocer la evolución de las poblaciones extranjeras residentes en Francia.

Por su intensidad, su diversidad y su antigüedad, la inmigración española en Francia es un ejemplo interesante de estudiar.

Desde los años 1960, la población española en Francia se distribuye por las mismas zonas pero se ha reducido de casi un $65 \%$. Esto se debe tanto a los retornos como a las nacionalizaciones y en menor medida al saldo natural de este colectivo. Hay que precisar sin embargo que observando el total de los españoles y franceses de origen español, esta reducción no ha sido ni mucho menos tan intensa.

PALABRAS Clave: Emigrantes españoles, Francia, distribución territorial.

RÉSUMÉ: Malgré les problèmes juridiques que présentent les recensements de population français en ce qui concerne le nombre d'étrangers, il s'agit d'une bonne source d'informations pour la connaissance de l'évolution des populations étrangères résidentes en France.

Son intensité, sa diversité et son ancienneté font de l'inmigration espagnole en France un exemple très intéressant à étudier.

Depuis les années 1960, la population espagnole en France se distribue dans les même regions, mais elle a diminué de près de $65 \%$. Cette baisse se doit aux retours, à l'acquisition de la nationalité française et en moindre mesure au solde naturel de cette population. Précisons cependant, que si l'on observe l'ensemble des espagnols et des français d'orgine espagnole, cette diminution est loin d'être aussi significative.

ABSTRACT: Despite the legal problems that frech population census arise when assessing the number of foreigners, they are a good way to know how foreign population leaving in France evolve.

On account of its size, its diversity and its age, spanish immigration in France is worth being studied as an esample.

Since the 1960's this population has spread out over the same areas, but it has almost decrease by $65 \%$. This is essentially due to immigrants going back to Spain as well as naturalizations, but also to the natural growth of this community. However if we consider Spaniards and Frech people native from Spain as a whole, this decrease is not that important. 